\title{
R-SWAT-FME User's Guide
}

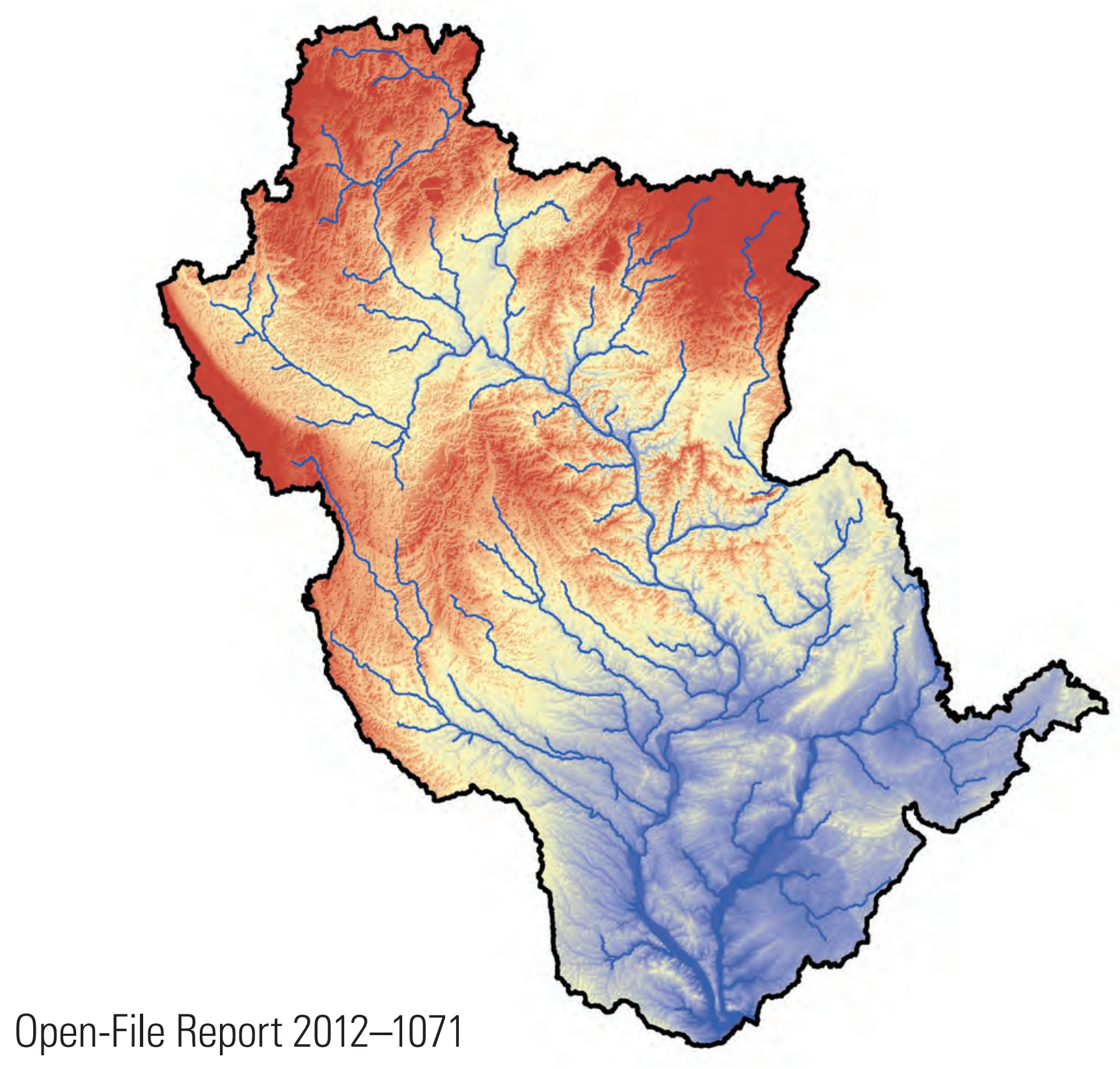

U.S. Department of the Interior

U.S. Geological Survey 



\section{R-SWAT-FME User's Guide}

By Yiping Wu and Shuguang Liu

Open-File Report 2012-1071

U.S. Department of the Interior

U.S. Geological Survey 


\section{U.S. Department of the Interior \\ KEN SALAZAR, Secretary \\ U.S. Geological Survey \\ Marcia K. McNutt, Director}

U.S. Geological Survey, Reston, Virginia: 2012

For more information on the USGS - the Federal source for science about the Earth, its natural and living resources, natural hazards, and the environment, visit http://www.usgs.gov or call 1-888-ASK-USGS.

For an overview of USGS information products, including maps, imagery, and publications, visit http://www.usgs.gov/pubprod

To order USGS information products, visit http://store.usgs.gov

Any use of trade, product, or firm names is for descriptive purposes only and does not imply endorsement by the U.S. Government.

Although this report is in the public domain, permission must be secured from the individual copyright owners to reproduce any copyrighted materials contained within this report.

Suggested citation:

Wu, Yiping, and Liu, Shuguang, 2012, R-SWAT-FME user's guide: U.S. Geological Survey Open-File Report 2012-1071, $5 \mathrm{p}$. 


\section{Contents}

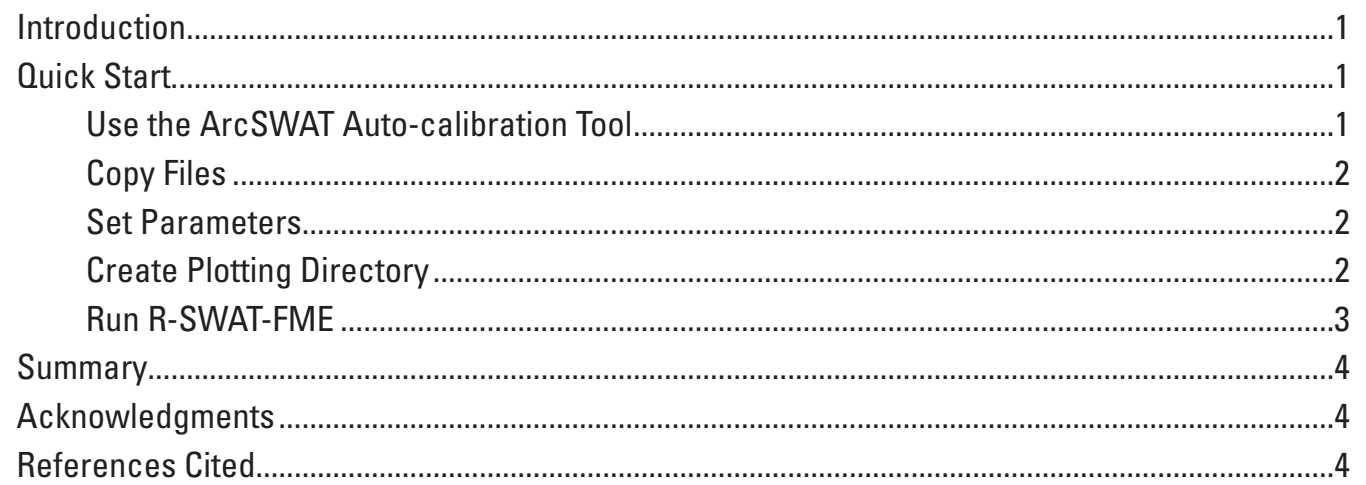

\section{Figures}

1. Screenshot of the R-SWAT-FME run with option 1 ........................................................... 3

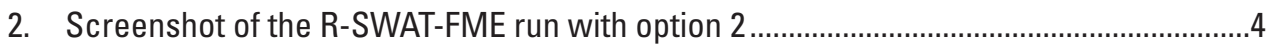





\title{
R-SWAT-FME User's Guide
}

\author{
By Yiping Wu'and Shuguang Liu²
}

\section{Introduction}

R program language-Soil and Water Assessment Tool-Flexible Modeling Environment (R-SWAT-FME) (Wu and Liu, 2012) is a comprehensive modeling framework that adopts an R package, Flexible Modeling Environment (FME) (Soetaert and Petzoldt, 2010), for the Soil and Water Assessment Tool (SWAT) model (Arnold and others, 1998; Neitsch and others, 2005). This framework provides the functionalities of parameter identifiability, model calibration, and sensitivity and uncertainty analysis with instant visualization.

This user's guide shows how to apply this framework for a customized SWAT project. Users have two ways to execute this modeling framework: (1) run the executable (RSWATFME.EXE), which is supported by the RFortran (Thyer and others, 2011) and Open Multi-Processing (OpenMP), or (2) run the R script (yp_SWATDLL FME.R), which calls RSWATFME.DLL, in the $\mathrm{R}$ prompt window. Users that have access to the developed R function, R-SWAT, could also use other potential R packages for SWAT by simply calling functions R-SWAT(pars) or R-SWATcost(pars).

\section{Quick Start}

The development of R-SWAT-FME is based on the SWAT built-in auto-calibration procedure and uses the same input files. Therefore, a SWAT project, prepared for the model's auto-calibration with the Shuffled Complex Evolution (SCE) algorithm (Duan and others, 1992; Green and van Griensven, 2008; van Griensven and others, 2006), is also ready to use the R-SWATFME framework. R-SWAT-FME users need to follow the procedures in this section to avoid possible errors.

\section{Use the ArcSWAT Auto-calibration Tool}

It is highly recommended to use the existing auto-calibration tool available in the ArcSWAT interface (Winchell and others, 2009) to prepare input files (such as changepar.dat, objmet.dat, responsmet.dat, ObsData.dat) required by R-SWAT-FME. Detailed information about these files can be found in the SWAT 2005 auto-calibration manual (van Griensven, 2006).

Users need to make sure the model print time step (iprint $=0 / 1 / 2$ in "file.cio") agrees with the print time step for calibration and observation data. Before running the framework, users need to run the officially published SWAT model (SWAT2005.exe) with auto-calibration activated (iclb=2 in "file.cio") to verify it works. If it does work, then users complete the following steps:

1. stop SWAT2005.exe with ctrl+C,

2. manually change iclb to 0 and run SWAT2005.exe (required only if RSWATFME.DLL is the user's option),

3. manually change iclb to 11 if RSWATFME.EXE is the user's option (denoted as option 1 hereafter) or 12 if RSWATFME.DLL is the user's option (denoted as option 2 hereafter).

If the user's system supports OpenMP, then SWAT2005.exe can also be replaced by RSWATFME.EXE when implementing steps 1 and 2 .

${ }^{1}$ ASRC Research and Technology Solutions, contractor to U.S. Geological Survey, Sioux Falls, South Dakota.

${ }^{2}$ U.S, Geological Survey, Sioux Falls, South Dakota. 


\section{Copy Files}

Copy the following files from the released package of the framework to the user's local project directory:

1. RSWATFME.EXE

This file is only required for option 1 .

2. RSWATFME.DLL

This file is only required for option 2 .

3. yp_FME_Func.R

This file contains some basic R functions required for both options 1 and 2. Changes to this file can only be made if users understand the purpose of each function.

4. yp_SWAT_FME.R

This file is only required for option 1 and demonstrates how the R-SWAT-FME works through calling some major FME functions. Users can modify the file, as needed, to use other R packages or functions. The R-SWAT function is named SWAT(pars) for option 1 and RSWAT(pars) for option 2.

5. yp_SWATDLL_Func.R

This file is only required for option 2 and contains some extra $\mathrm{R}$ functions used for the framework. Changes to this file can only be made if users understand the purpose of each function.

6. yp_SWATDLL_FME.R

This file is only required for option 2 and shows how the R-SWAT-FME works through calling some major FME functions. Users are encouraged to modify the file, as needed, to use other R packages or functions.

7. LOG.IN

This file is required for both option 1 and 2. Users are not allowed to change this file as the parameters inside it are not related to the framework and they can only be recognized by the developers.

\section{Set Parameters}

- mxNiter: maximum iterations.

This parameter is defined by the user (default $=1000)$ in yp_SWAT_FME.R and yp_SWATDLL_FME.R and used by functions: yp_FME_pseudoOptim and yp_FME_MCMC.

- cmeth: code for the optimization method.

This parameter is defined by the user (default = "Pseudo") in yp_SWAT_FME.R and yp_SWATDLL_FME.R. More methods are available in the FME package, but Pseudo is recommended and has been tested successfully (Wu and Liu, 2012).

\section{Create Plotting Directory}

Users need to make a directory called "Figures" directly under their SWAT project directory to save the figures generated by the framework. 


\section{Run R-SWAT-FME}

Users can run the R-SWAT-FME framework in two ways: (1) execute RSWATFME.EXE or (2) execute yp_SWATDLL_FME.R in the R window. Figure 1 and figure 2 show the screenshots of the R-SWAT-FME run with option 1 and option 2, respectively. For option 2, users need to read the short instruction given in the first few lines of the R script. Option 1 is recommended as it shows the progress of the model run and the R script run; however, the user's system must support OpenMP. A detailed comparison of the two options was given by $\mathrm{Wu}$ and Liu (2012).

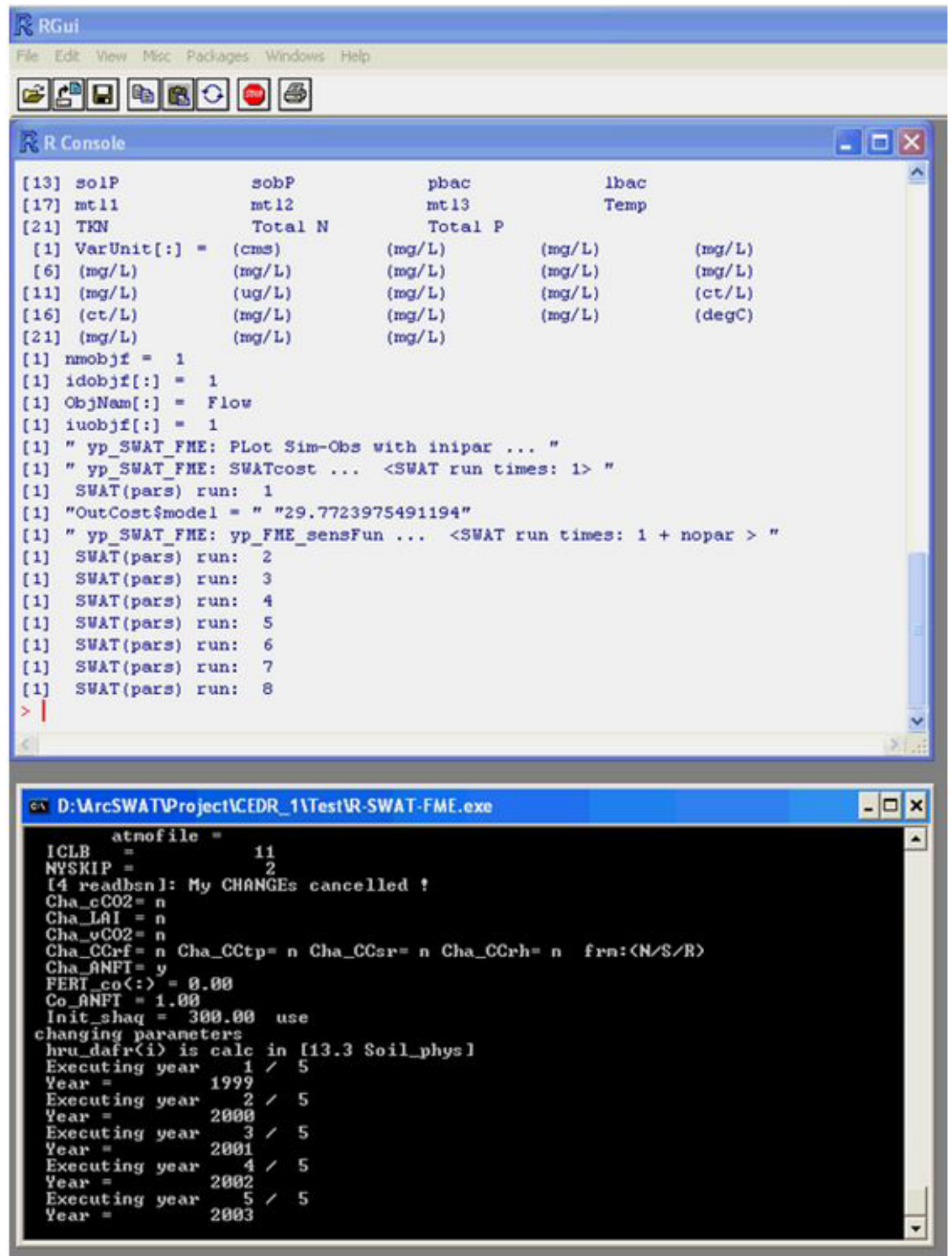

Figure 1. Screenshot of the R-SWAT-FME run with option 1. 


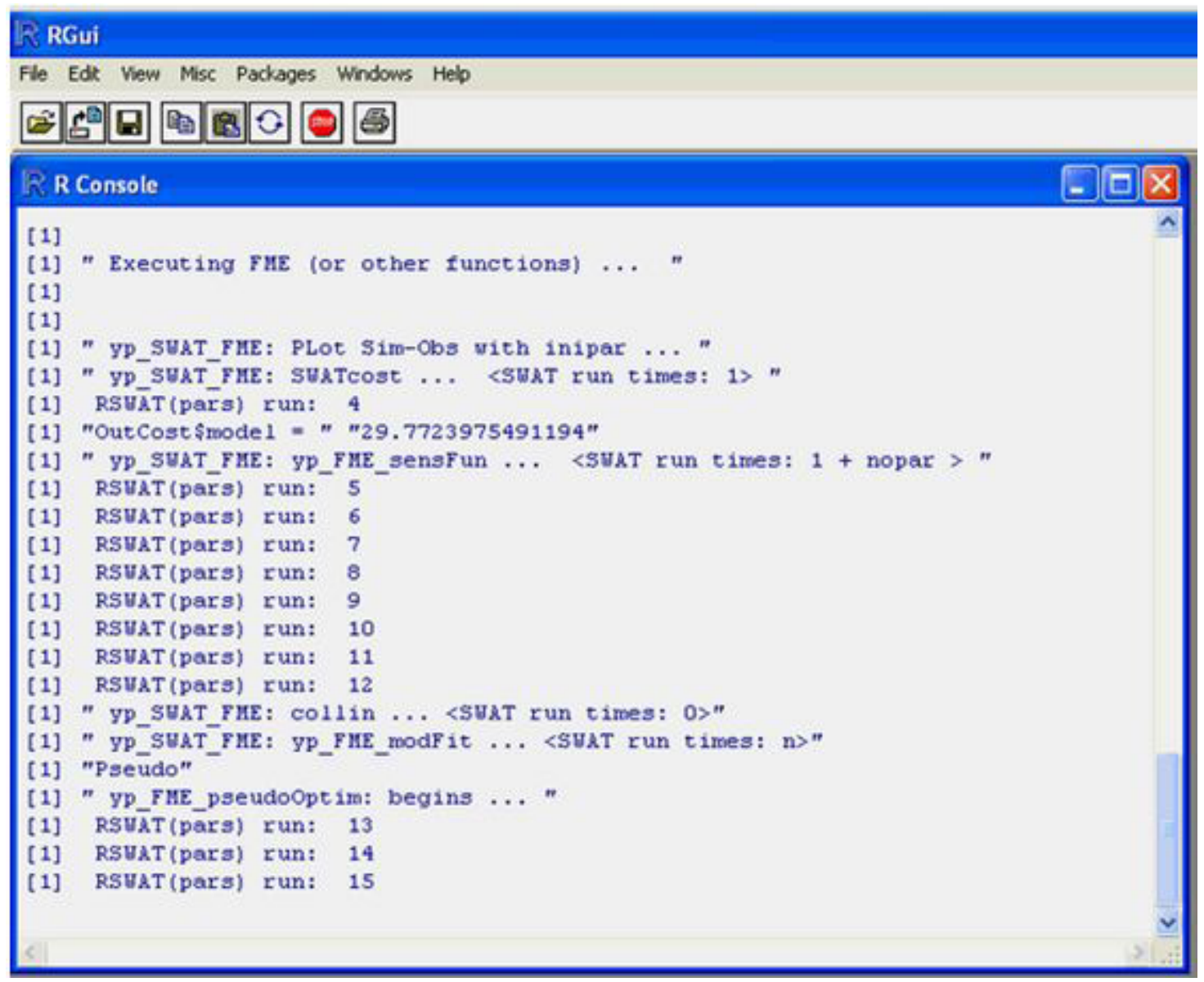

Figure 2. Screenshot of the R-SWAT-FME run with option 2.

\section{Summary}

The R-SWAT-FME is free and users may modify the R scripts as needed. Users may contact the developers for trouble shooting or sharing their improvements to these scripts. In addition, to wrap the FME package with other Fortran or $\mathrm{C} / \mathrm{C}++$ based environmental models, we suggest users see Wu and Liu (2012) for help. More information about FME functions is available from the Comprehensive R Archive Network at $h t t p: / / C R A N . R$-project.org/package $=F M E$, and information about using

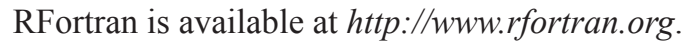

\section{Acknowledgments}

The development of the modeling framework and this User's Guide were funded by LandCarbon project (GEMS Modeling), the NASA Land Cover and Land Use Change Program (Grant NNH07ZDA001N), and the U.S. Geological Survey Geographic Analysis and Monitoring (GAM) Program. Work for this project was performed under USGS contract G08PC91508.

The authors wish to thank Lei Ji, Matthew Rigge, Thomas Adamson, and Elisabeth Brouwers for their comments on this Open-File Report.

\section{References Cited}

Arnold, J.G., Srinivasan, R., Muttiah, R.S., and Williams, J.R., 1998, Large area hydrologic modeling and assessment; part 1Model development: Journal of the American Water Resources Association, v. 34, p. 73-89. 
Duan, Q.Y., Sorooshian, S., and Gupta, V., 1992, Effective and efficient global optimization for conceptual rainfall-runoff models: Water Resources Research, v. 28, p. 1,015-1,031.

Green, C.H., and Griensven, A. van, 2008, Autocalibration in hydrologic modeling-Using swat2005 in small-scale watersheds: Environmental Modelling \& Software, v. 23, p. 422-434.

Griensven, A. van, 2006, Sensitivity, auto-calibration, uncertainty and model evaluation in SWAT2005, p. 48, accessed March 6, 2012, at http://biomath.ugent.be/ ann/swat_manuals/SWAT2005_manual_sens_cal_unc.pdf.

Griensven, A. van, Meixner, T., Grunwald, S., Bishop, T., Diluzio, A., and Srinivasan, R., 2006, A global sensitivity analysis tool for the parameters of multi-variable catchment models: Journal of Hydrology, v. 324, p. 10-23.

Neitsch, S.L., Arnold, J.G., Kiniry, J.R., Williams, J.R., and King, K.W., 2005, Soil and water assessment tool theoretical documentation (ver. 2005): Temple, Tex., GSWR Agricultural Research Service \& Texas Agricultural Experiment Station.

Soetaert, K., and Petzoldt, T., 2010, Inverse modelling, sensitivity and monte carlo analysis in R using package FME: Journal of Statistical Software, v. 33, p. 1-28.

Thyer, M., Leonard, M., Kavetski, D., Need, S., and Renard, B., 2011, The open source RFortran library for accessing R from Fortran, with applications in environmental modelling: Environmental Modelling \& Software, v. 26, p. 219-234.

Winchell, M., Srinivasan, R., Di Luzio, M., and Arnold, J.G., 2009, ArcSWAT 2.3.4 interface for SWAT2005 (ver. 2005): Temple, Tex., GSWR Agricultural Research Service \& Texas Agricultural Experiment Station.

Wu, Y., and Liu, S., 2012, Automating calibration, sensitivity and uncertainty analysis of complex models using the R package flexible modeling environment (FME) - SWAT as an example: Environmental Modelling \& Software, v. 31, p. 99-109.

Publishing support provided by:

Rolla Publishing Service Center

For more information concerning this publication, contact:

U.S. Geological Survey Earth Resources Observation and Science (EROS) Center

47914 252nd Street

Sioux Falls, South Dakota 57198

(605) 594-6151

Or visit the EROS Center Web site at: http://eros.usgs.gov/ 


